\title{
AN OBSERVATIONAL STUDY OF GAIT SPEED IN ELDERLY PARTICIPANTS ATTENDING OUTPATIENT CLINIC GERIATRIC DEPARTMENT, MADRAS MEDICAL COLLEGE, CHENNAI
}

\author{
Kesavan Umakalyani ${ }^{1}$, Manickam Senthil Kumar ${ }^{2}$ \\ ${ }^{1}$ Assistant Professor, Department of Geriatric Medicine, Madras Medical College, Chennai, Tamilnadu. \\ ${ }^{2}$ Assistant Professor, Department of Geriatric Medicine, Madras Medical College, Chennai, Tamilnadu.
}

\section{ABSTRACT}

\section{BACKGROUND}

Gait speed is a clinical marker of functional capacity among the elderly. Gait speed is an important measure in comprehensive geriatric assessment. Gait speed is a quick, inexpensive, reliable measure of functional capacity with well-documented predictive value for major health-related outcomes. ${ }^{2}$ Numerous epidemiological studies have documented gait speed in healthy, communitydwelling older people.

The aim of the study is to observe the gait speed of elderly patients attending Geriatric Outpatient Clinic, Rajiv Gandhi Government General Hospital, Chennai using 4 metres (15 ft.) walking test and study the same with respect to Gender and Body Mass Index (BMI).

\section{MATERIALS AND METHODS}

Gait speed is a measure of how quickly someone can walk within a specified distance. It requires input from the brain, spinal cord, peripheral nerves, muscles, joints and cardiovascular system. When you measure gait speed, the score can give you insight int o the overall health of specific populations. Measure out your desired gait test distance, for example- measure out a 4 metre walking area. In addition, measure out a 5 foot starting area and a 5 foot finishing area. The purpose of the starting and finishing area is to allow the person to build up speed to either their comfortable or maximal gait speed. ${ }^{1} 204$ elderly patients were randomly selected. The data was collected and analysed using $\mathrm{T}$ test. The 4 metres (15 ft) walk test was the tool used to evaluate the maximum gait speed and average gait speed. To eliminate the acceleration and deceleration components, the volunteers were instructed to begin walking $1.2 \mathrm{~m}$ before the beginning of the course and to finish $1.2 \mathrm{~m}$ after the end of the course at usual speed. Three tests were carried out to minimise the learning effect, and the best performance was used for data analysis. A single examiner using a digital stopwatch with $1 / 100$ of a second reading recorded the walking time of all volunteers and registered the number of steps and strides taken during the course. Gender, height and weight of the elderly patients were recorded for calculating Body Mass Index.

Design- A hospital-based, prospective, observational study.

\section{RESULTS}

There is no significant difference between gait speed maximum between age group. There is significant difference between gait speed and age group of 70 - 79 years having lower values than the 80+ years. There is significant difference between BMI and age group 60 - 69 years having higher values than the other groups.

\section{CONCLUSION}

Gait speed has been shown to be an important measure in comprehensive geriatric assessment in all clinical settings for the purposes of developing risk profiles and care plans for geriatric patients.

\section{KEYWORDS}

Gait Speed, Geriatric, Elderly.

HOW TO CITE THIS ARTICLE: Umakalyani K, Kumar MS. An observational study of gait speed in elderly participants attending outpatient clinic geriatric department, Madras Medical College, Chennai. J. Evolution Med. Dent. Sci. 2018;7(11):1356-1359, DOI: $10.14260 /$ jemds $/ 2018 / 308$

\section{BACKGROUND}

Gait speed is a clinical marker of functional capacity among the elderly. Gait speed is an important measure in comprehensive geriatric assessment. Gait speed is a quick, inexpensive, reliable measure of functional capacity with well-documented predictive value for major health-related outcomes. $^{2}$

'Financial or Other Competing Interest': None.

Submission 31-01-2018, Peer Review 24-02-2018,

Acceptance 03-03-2018, Published 12-03-2018.

Corresponding Author:

Manickam Senthil Kumar,

F1 Sorgam Flats, 9, Parthasarathy Nagar,

$8^{\text {th }}$ Street Extn., Adambakkam, Chennai, Tamilnadu.

E-mail:drmsenthilk@gmail.com

DOI: $10.14260 /$ jemds $/ 2018 / 308$

\section{(c) $\bigcirc(5)$}

Numerous epidemiological studies have documented gait speed in healthy, community-dwelling older people. The purpose of this study is to undertake a systematic review and meta-analysis of gait speed in a specific age group with gender and BMI of elderly patients attending Geriatric OPD in Rajiv Gandhi Government General Hospital, Madras Medical College, Chennai.

The ability to walk underlies many basic and community functions necessary for independence. Slowing of movement with ageing appears to be a universal biological phenomenon and is likely to reflect the integrated performance of numerous organ systems. Factors that influence walking ability can be classified into six main physiological subsystems: central nervous system, perceptual system, peripheral nervous system, muscles, bone and/or joints, and energy production and/or delivery. ${ }^{3}$ When these systems 
become dysfunctional, for example as a consequence of an acute medical condition such as stroke or hip fracture or as a result of frailty-associated progressive decline, walking slows. The appearance of difficulties in walking marks a critical point, such that assessment of gait speed has been described as the "sixth vital sign" with the potential to serve as a core indicator of health and function in ageing and disease. 4

Of the available physical performance measures, gait speed represents one that is suitable to be implemented in the standard clinical evaluation of older persons because it is a quick, inexpensive, reliable measure of functional capacity with high interrater and test-retest reliability. ${ }^{5}$ It has welldocumented predictive value for major health-related outcomes such as hospitalisations, nursing home placements, mortality, poor quality of life, physical and cognitive functional decline and falls, making it a useful screening measure to identify older persons at risk of such events. Moreover, it has been used as an outcome measure in rehabilitation and in trials of interventions to delay the onset of disability or frailty. ${ }^{6}$ Advantages are that the test of gait speed is easy to administer, does not require laboratory equipment and is not limited to a specific health care discipline.

However, a recent systematic review of the assessment of gait speed found that protocols for walking tests vary widely, influencing interpretations of physical performance. Timed walking tests varied according to pace (usual or maximal speed), whether static or moving start, distance walked (ranging from 4 to $500 \mathrm{~m}$ ), and characteristics of the study group. ${ }^{2}$ The lack of consensus regarding walk test protocol may limit intergroup comparisons and broader standardisation of norms.

Judgments about how an individual's gait speed compares with those of the population, to which they belong require the availability of reference values. Numerous large scale epidemiological studies have documented gait speed in healthy, community-dwelling older people and normative values have been established specific to this group. ${ }^{7}$ However, there is limited data for groups with mobility limitations. The clinical application of gait speed would benefit from estimates of the distribution of performance scores that are specific to subgroups based on among other things age, gender and setting, taking into account test protocol.

The purpose of this article, therefore, is to undertake a systematic review and meta-analysis of gait speed for geriatric patients attending Geriatric OPD in Rajiv Gandhi Government General Hospital Chennai.

Despite its widespread use in clinical practice, there are no universally accepted gait classifications. This gait classification is a part of the standard neurological examination that also tests cranial nerves, strength, sensation and deep tendon reflexes. ${ }^{6}$ Gait is clinically rated as either "normal" or "abnormal" following visual inspection of walking patterns. ${ }^{8}$ Abnormal gaits are further classified as either neurological or non-neurological (due to causes such as arthritis or dyspnoea).

\section{Aims and Objectives}

The aim of the study is to observe the gait speed of elderly patients attending Geriatric Outpatient Clinic, Rajiv Gandhi Government General Hospital, Chennai using 4 metres (15 ft.) walking test and study the same with respect to Gender and Body Mass Index (BMI).

\section{Study Design}

Prospective observational study.

\section{Inclusion Criteria}

Above 60 years patients attending Geriatric outpatient clinic, Rajiv Gandhi Government General Hospital, Madras Medical College, Chennai, were willing to participate.

\section{Exclusion Criteria}

History of stroke, dementia and alcoholism, chronic intake of drugs affecting cognition, severe visual and hearing impairment and using aids for walking patients are excluded. The selected participants were subjected to the test by a trained physiotherapist and the data were documented and entered. Date of birth of the participants were confirmed with their available government identification records. If not available, it was approximately calculated with their age at marriage and age of their first child. Height and weight were recorded. Functional status was noted. Only functionally independent elders were taken for study.

\section{MATERIALS AND METHODS}

Gait speed is a measure of how quickly someone can walk within a specified distance. It requires input from the brain, spinal cord, peripheral nerves, muscles, joints and cardiovascular system. ${ }^{9}$ When you measure gait speed, the score can give you insight into the overall health of specific populations. Measure out your desired gait test distance. For example, measure out a 4-metre walking area. In addition, measure out a 5-foot starting area and a 5-foot finishing area. The purpose of the starting and finishing area is to allow the person to build up speed to either their comfortable or maximal gait speed.

By using power analysis formula, prevalence of gait disorders was $32.2 \%{ }^{10}$ with allowable error of $6.4 \%$ the total sample size was 204 . These 204 elderly patients $(100$ males and 104 females) were randomly selected by every sixth elderly patients attending the geriatric outpatient clinic by using probability systematic random sampling technique attending the geriatric outpatient department of Geriatric Outpatient Clinic, Rajiv Gandhi Government General Hospital, Chennai. After obtaining the informed consent from each individual and they are subjected to 4 metres $(15 \mathrm{ft})$ walking test. To eliminate the acceleration and deceleration components, the volunteers were instructed to begin walking $1.2 \mathrm{~m}$ before the beginning of the course and to finish $1.2 \mathrm{~m}$ after the end of the course at usual speed. ${ }^{4}$ Three tests were carried out to minimise the learning effect, and the best performance was used for data analysis. A single examiner using a digital stopwatch with $1 / 100$ th of a second reading recorded the walking time of all volunteers and registered the number of steps and strides taken during the course. Gender, Height and Weight of the elderly patients are recorded for calculating Body Mass Index.

\section{Statistical Analysis}

The data was collected and analysed using IBM SPSS Version 20.0. Frequency and Percentages was used for describing the patient's demographic profiles. Independent ' $t$ ' test was used 
for significant difference of the Gait speed between Male and Female. One-Way ANOVA was used for significant difference between gait speed and age group, BMI respectively. Pearson's correlation was used to check the relationship between BMI and Gait speed.

\section{RESULTS}

- There is no significant difference between gait speed maximum between age group.
- There is significant difference between gait speed and age group 70 - 79 years having lower values than the $80+$ years.

- There is significant difference between BMI and age group 60 - 69 years having higher values than the other groups.

\begin{tabular}{|c|c|c|}
\hline Age Group & Frequency & Percent \\
\hline 60-69 Years & 99 & 48.5 \\
\hline 70-79 Years & 62 & 30.4 \\
\hline 80 Years and Above & 43 & 21.1 \\
\hline Total & 204 & 100.0 \\
\hline Sex & Frequency & Percent \\
\hline Male & 100 & 49.0 \\
\hline Female & 104 & 51.0 \\
\hline Total & 204 & 100.0 \\
\hline
\end{tabular}

\begin{tabular}{|c|c|c|c|c|c|c|c|c|c|c|}
\hline \multicolumn{10}{|c|}{ Descriptives } & \multirow{3}{*}{ F value } \\
\hline & & \multirow{2}{*}{$\mathbf{N}$} & \multirow{2}{*}{ Mean } & \multirow{2}{*}{$\begin{array}{c}\text { Std. } \\
\text { Deviation }\end{array}$} & \multirow{2}{*}{$\begin{array}{l}\text { Std. } \\
\text { Error }\end{array}$} & \multicolumn{2}{|c|}{$\begin{array}{l}\text { 95\% Confidence } \\
\text { Interval for Mean }\end{array}$} & \multirow{2}{*}{ Minimum } & \multirow{2}{*}{ Maximum } & \\
\hline & & & & & & $\begin{array}{l}\text { Lower } \\
\text { Bound }\end{array}$ & $\begin{array}{l}\text { Upper } \\
\text { Bound }\end{array}$ & & & \\
\hline \multirow{4}{*}{$\begin{array}{l}\text { Gait Speed } \\
\text { Maximum }\end{array}$} & 60-69 yrs. & 99 & 8.18 & 3.45 & 0.35 & 7.49 & 8.87 & 5.00 & 25.00 & \multirow{4}{*}{3.038} \\
\hline & 70-79 yrs. & 62 & 7.39 & 1.80 & 0.23 & 6.93 & 7.85 & 4.00 & 12.00 & \\
\hline & $\begin{array}{c}80 \text { yrs. and } \\
\text { above }\end{array}$ & 43 & 8.77 & 2.78 & 0.42 & 7.91 & 9.62 & 5.00 & 15.00 & \\
\hline & Total & 204 & 8.06 & 2.93 & 0.20 & 7.66 & 8.47 & 4.00 & 25.00 & \\
\hline \multirow{4}{*}{$\begin{array}{l}\text { Average } \\
\text { Gait Speed }\end{array}$} & 60-69 yrs. & 99 & 7.75 & 3.08 & 0.31 & 7.13 & 8.36 & 4.00 & 20.00 & \multirow{4}{*}{$3.204^{*}$} \\
\hline & 70-79 yrs. & 62 & 7.05 & 2.01 & 0.26 & 6.54 & 7.56 & 4.00 & 12.00 & \\
\hline & $\begin{array}{c}80 \text { yrs. and } \\
\text { above }\end{array}$ & 43 & 8.40 & 2.69 & 0.41 & 7.57 & 9.22 & 5.00 & 15.00 & \\
\hline & Total & 204 & 7.67 & 2.74 & 0.19 & 7.29 & 8.05 & 4.00 & 20.00 & \\
\hline \multirow{4}{*}{ BMI } & 60-69 yrs. & 99 & 24.96 & 4.57 & 0.46 & 24.05 & 25.87 & 16.59 & 35.06 & \multirow{4}{*}{$5.572^{* *}$} \\
\hline & 70-79 yrs. & 62 & 23.18 & 5.12 & 0.65 & 21.88 & 24.48 & 9.91 & 39.48 & \\
\hline & $\begin{array}{l}80 \text { yrs. and } \\
\text { above }\end{array}$ & 43 & 22.49 & 3.36 & 0.51 & 21.46 & 23.53 & 15.21 & 30.82 & \\
\hline & Total & 204 & 23.90 & 4.63 & 0.32 & 23.26 & 24.54 & 9.91 & 39.48 & \\
\hline
\end{tabular}

${ }^{*} \mathrm{p}<0.05^{* *} \mathrm{p}<0.01$

\section{Comparison Gait Speed by Sex}

\begin{tabular}{|c|c|c|c|c|c|c|c|}
\hline \multicolumn{6}{|c|}{ Independent 'T' Test } & \multirow[b]{2}{*}{ T value } & \multirow[b]{2}{*}{ P value } \\
\hline & Sex & $\mathbf{N}$ & Mean & Std. Deviation & Std. Error Mean & & \\
\hline \multirow{2}{*}{$\begin{array}{l}\text { Gait Speed } \\
\text { Maximum }\end{array}$} & Male & 100 & 7.80 & 2.10 & 0.21 & \multirow{2}{*}{1.263} & \multirow{2}{*}{0.208} \\
\hline & Female & 104 & 8.32 & 3.54 & 0.35 & & \\
\hline \multirow{2}{*}{$\begin{array}{l}\text { Average Gait } \\
\text { Speed }\end{array}$} & Male & 100 & 7.70 & 2.19 & 0.22 & \multirow{2}{*}{0.145} & \multirow{2}{*}{0.885} \\
\hline & Female & 104 & 7.64 & 3.20 & 0.31 & & \\
\hline
\end{tabular}

No difference between gait speed for both sexes.

\section{Correlation between BMI with Gait Speed}

\begin{tabular}{|c|c|c|c|}
\hline \multicolumn{2}{|c|}{} & Gait Speed Maximum & Average Gait Speed \\
\hline \multirow{3}{*}{ BMI } & Pearson Correlation & .058 & .011 \\
\cline { 2 - 4 } & P value & .412 & .877 \\
\cline { 2 - 4 } & $\mathrm{N}$ & 204 & 204 \\
\hline
\end{tabular}

No relationship between BMI and gait speed. 


\begin{tabular}{|c|c|c|c|c|c|c|c|c|c|c|c|}
\hline \multicolumn{12}{|c|}{ Descriptives } \\
\hline & & \multirow{2}{*}{$\mathbf{N}$} & \multirow{2}{*}{ Mean } & \multirow{2}{*}{$\begin{array}{c}\text { Std. } \\
\text { Deviation }\end{array}$} & \multirow{2}{*}{$\begin{array}{l}\text { Std. } \\
\text { Error }\end{array}$} & \multicolumn{2}{|c|}{$\begin{array}{l}\text { 95\% Confidence } \\
\text { Interval for Mean }\end{array}$} & \multirow{2}{*}{ Minimum } & \multirow{2}{*}{ Maximum } & \multirow{2}{*}{ F Value } & \multirow{2}{*}{ P Value } \\
\hline & & & & & & $\begin{array}{l}\text { Lower } \\
\text { Bound }\end{array}$ & $\begin{array}{l}\text { Upper } \\
\text { Bound }\end{array}$ & & & & \\
\hline \multirow{5}{*}{$\begin{array}{c}\text { Gait } \\
\text { Speed } \\
\text { Maximum }\end{array}$} & $<18.5$ & 17 & 7.35 & 1.93 & 0.47 & 6.36 & 8.35 & 5.00 & 11.00 & \multirow{5}{*}{2.061} & \multirow{5}{*}{0.107} \\
\hline & $18.5-24.99$ & 112 & 7.85 & 2.43 & 0.23 & 7.39 & 8.30 & 4.00 & 20.00 & & \\
\hline & $25-30$ & 50 & 8.92 & 3.98 & 0.56 & 7.79 & 10.05 & 5.00 & 25.00 & & \\
\hline & 30 and above & 25 & 7.80 & 2.87 & 0.57 & 6.61 & 8.99 & 5.00 & 16.00 & & \\
\hline & Total & 204 & 8.06 & 2.93 & 0.20 & 7.66 & 8.47 & 4.00 & 25.00 & & \\
\hline \multirow{5}{*}{$\begin{array}{c}\text { Average } \\
\text { Gait } \\
\text { Speed }\end{array}$} & $<18.5$ & 17 & 6.94 & 1.82 & 0.44 & 6.01 & 7.88 & 5.00 & 10.00 & \multirow{5}{*}{2.40} & \multirow{5}{*}{0.069} \\
\hline & $18.5-24.99$ & 112 & 7.56 & 2.47 & 0.23 & 7.10 & 8.03 & 4.00 & 20.00 & & \\
\hline & $25-30$ & 50 & 8.48 & 3.58 & 0.51 & 7.46 & 9.50 & 4.00 & 20.00 & & \\
\hline & 30 and above & 25 & 7.04 & 2.21 & 0.44 & 6.13 & 7.95 & 5.00 & 13.00 & & \\
\hline & Total & 204 & 7.67 & 2.74 & 0.19 & 7.29 & 8.05 & 4.00 & 20.00 & & \\
\hline
\end{tabular}

No difference between gait speed with BMI.

\section{DISCUSSION}

- In our study, out of 204 elderly patients $49 \%$ (100) were males and $51 \%$ (104) were females. No difference between gait speed was observed for gender. $60-69$ years' age group patients were $49 \%$ (99), 70 - 79 years' age group were $30 \%$ (62) and 80 years and above were $21 \%$ (43). There is no difference between gait speed maximum between age groups.

- There is significant difference between average gait speed and age group with 'p' value of $p<0.05,70-79$ years having lower values than the $80+$ years.

- There is significant difference between BMI and age group with 'p' value of $\mathrm{p}<0.01,60$ - 69 years having higher values than the other groups.

- $\quad$ No difference between gait speed with BMI.

\section{CONCLUSION}

Gait speed has been shown to be an important measure in comprehensive geriatric assessment in all clinical settings for the purposes of developing risk profiles and care plans for geriatric patients.

\section{ACKNOWLEDGEMENTS}

I thank my hospital patients, their care givers, colleagues and statistician for the conduct of this study.

\section{REFERENCES}

[1] Cesari M. Role of gait speed in the assessment of older patients. JAMA 2011;305(1):93-4.

[2] Lubitz J, Cai L, Kramarow E, et al. Health, life expectancy and health care spending among the elderly. N Engl J Med 2003;349(11):1048-55.

[3] Studenski S. Bradypedia: is gait speed ready for clinical use? J Nutr Health Aging 2009;13(10):878-80.

[4] Studenski S, Perera S, Patel K, et al. Gait speed and survival in older adults. JAMA 2011;305(1):50-8.

[5] Fritz S, Lusardi M. White paper: walking speed: the sixth vital sign. J Geriatr Phys Ther 2009;32(2):46-9.

[6] Studenski S, Perera S, Wallace D, et al. Physical performance measures in the clinical setting. J Am Geriatr Soc 2003;51(3):314-22.

[7] Graham JE, Ostir GV, Fisher SR, et al. Assessing walking speed in clinical research: a systematic review. J Eval Clin Pract 2008;14(4):552-62.

[8] Hall WJ. Update in geriatrics. Ann Intern Med 2006;145(7):538-43.

[9] Montero-Odasso M, Schapira M, Soriano ER, et al. Gait velocity as a single predictor of adverse events in healthy seniors aged 75 years and older. J Gerontol A Biol Sci Med Sci 2005;60(10):1304-9.

[10] Mahlknecht P, Kiechl S, Bloem BR, et al. Prevalence and burden of gait disorders in elderly men and women aged 60-97 years: a population-based study. PLoS One 2013;8(7): e69627. 